\title{
A SEIVA E O TRAÇO: HISTÓRIA, NATUREZA E NARRATIVA NO DIÁRIO DE VIAGEM DE FRANCISCO FREIRE ALEMÃO (1859-1861)
}

Karoline Viana Teixeira*

\begin{abstract}
Resumo
O presente artigo analisa o projeto de identidade nacional do Instituto Histórico Geográfico Brasileiro (IHGB), tendo como objeto o diário de viagem do botânico Francisco Freire Alemão, membro do Instituto. Para o IHGB, a escrita da história de uma nação originada de sociedades iletradas passaria pelo estudo das ciências naturais, na busca de um ordenamento inteligível da natureza pela narrativa. Nesse sentido, pretendo depreender deste relato determinada prática de construção da memória e da temporalidade a partir da adoção de certos procedimentos narrativos, ligados às premissas da herança ilustrada e do historicismo romântico.
\end{abstract}

Palavras-chave: Identidade nacional; natureza; narrativa; escrita da História.

\section{Abstract}

This paper analyzes the project of national identity developed by Instituto Histórico e Geográfico Brasileiro (IHGB), having as subject Francisco Freire Alemão's travel diary. For IHGB, a national history writing of a country originated from illiterate societies pass through the study of natural sciences, in search of an intelligible order of nature through narrative. Accordingly, this report intends to infer particular practice of memory and temporality constructions from the adoption of certain narrative procedures, linked to the assumptions of inheritance illustrated and romantic historicism.

Keywords: National identity; nature; narrative; writing of History.

\footnotetext{
* Doutoranda em História Social (Universidade Federal do Ceará - UFC) e bolsista do Programa Reuni de Orientação e Operacionalização da Pós-Graduação Articulada à Graduação (Propag). E-mail: karoline_teixeira@hotmail.com.
} 
Diferente dos domínios espanhóis nos trópicos, que se dividiram em repúblicas fragmentadas após convulsionados processos revolucionários, a independência brasileira seguiu um caminho peculiar: não apenas conseguiu manter sua unidade territorial - ainda que ao custo de conflitos armados entre o poder central e as províncias rebeldes - como adotou um sistema de governo que tornou o Brasil a única monarquia bem-sucedida em toda a América. Para José Murilo de Carvalho, a monarquia representativa foi uma opção política entre outras possíveis para centralizar o poder estatal e evitar a fragmentação pela via republicana, articulada por uma elite política cuja "homogeneidade ideológica e de treinamento [...] iria reduzir os conflitos intra-elite e fornecer a concepção e a capacidade de implementar determinado modelo de dominação política" (Carvalho, 2011, p. 21).

Mas nem todos os que viviam no agora território brasileiro se sentiam necessariamente conectados a esta nova ordem. No dia 8 de setembro de 1859, em passagem pela cidade de Aracati, no Ceará, o botânico Francisco Freire Alemão registra em seu diário que a "gente do país" considerava as fronteiras do Brasil encerradas na própria província. Os que viviam para além delas seriam o outro, que para ali se dirigiam com o intuito de rapinar riquezas que eles mesmos desconheciam. "Eles fazem uma ideia tão exagerada da sua província, que no seu entender é em tudo superior a todas as outras" (Alemão, 2011, p. 62). O trecho mostra que, mesmo amainados os conflitos internos e garantido o reconhecimento internacional do Estado, restava a seguinte questão: como imprimir um caráter de nação civilizada a uma ex-colônia tornada país neófito e permeado por contradições? Um país escravista, monarquista e governado por descendentes da antiga metrópole, em muitos locais desprovido de documentos, monumentos e outros vestígios que permitissem a elaboração de uma cronologia histórica, como entendida pela cultura oitocentista?

$\mathrm{Na}$ segunda metade do século XIX, os momentos de estabilidade política e certa pujança econômica permitiram 
a arregimentação de forças em torno de um projeto ideológico, político e econômico para a integração nacional. Dentre os diversos componentes dessa elite política responsável por estabelecer a "construção da ordem", o presente trabalho voltar-se-á aos homens de letras: indivíduos com formação superior ou com notório saber preocupados em forjar simbolicamente a nação brasileira, reelaborando o conhecimento do passado sob a égide do progresso. "Além do desejo de fundar uma historiografia nacional e original, há a intenção de não só ensinar e divulgar conhecimentos, como formular uma história que, a exemplo dos demais modelos europeus, se dedicasse à exaltação e glória da pátria" (Schwarcz, 1993, p.102).

Reunidos em torno de instituições patrocinadas pelo imperador Pedro II, estes intelectuais buscavam equalizar, principalmente, os impasses para a definição de uma cronologia do "Novo Mundo" anterior à chegada do europeu nos séculos XV e XVI. Neste artigo vamos nos concentrar na atuação da elite letrada reunida em torno do Instituto Histórico e Geográfico Brasileiro (IHGB), analisando sua concepção de memória e como esta foi posta em prática num de seus projetos mais ambiciosos: a Comissão Científica de Exploração das Províncias do Norte, formada com o intuito de fazer conhecer as regiões mais distantes do Império recém-formado.

Vamos tomar como objeto o diário de viagem que o botânico Francisco Freire Alemão, chefe da expedição, redigiu durante a viagem à província do Ceará, entre 1859 e 1861. A ideia é examinar a participação de Freire Alemão neste complexo conjunto de tentativas e propostas de conhecimento da nação, levando em conta as formas de enunciação da escrita diarística do botânico como forma de apreensão e dominação de um espaço para quem se encontrava na posição de "estranho em terra estranha". Pretendo traçar um quadro de referências para a escrita diarística de Freire Alemão, num momento em que não apenas as fronteiras entre os campos de saber ainda se encontravam imiscuídas como também os sistemas de seleção, nomeação e catalogação das ciências da natureza se configuravam numa matriz segura para 
o trabalho de formação da identidade nacional, a partir de premissas científicas e, portanto, autorizadas.

\section{O IHGB e a construção da "antiguidade nacional"}

Fundado em 1838, o IHGB surge num período de mudanças que levariam à institucionalização do saber histórico, dando-lhe estatuto de ciência. As sociétés savantes que se difundiram no Ocidente ao longo do século XIX se constituíram num lugar privilegiado para pôr em prática o projeto de uma história, submetendo métodos e tradição da pesquisa antiquária ao crivo acadêmico a fim de conservar, pesquisar e divulgar suas respectivas histórias nacionais - ainda que a ruptura com o legado colecionista não tenha ocorrido de todo. Não por acaso, estas instituições manterão um intenso intercâmbio intelectual, afinando as posturas relativas ao tratamento da disciplina histórica em formação ou mesmo em busca de origens comuns através do compartilhamento de documentos e artefatos.

No Brasil, o IHGB representará, junto com outras instituições imperiais, um esforço destinado a estabelecer uma história nacional, intento particularmente difícil num país que, pelos critérios da cultura letrada europeia, era "desprovido de História". Um mesmo território abrigava em seu interior regiões de paisagens intocadas e populações em estado edênico, vilas e cidades arraigadas aos usos da antiga metrópole e uma Corte que aglutinava todas essas contradições a um só tempo, na medida em que, malgrado "língua, costumes, arquitetura e afluxo de produtos da indústria de todas as partes do mundo [que] dão à praça do Rio de Janeiro um aspecto europeu", logo se depara "com a turba de negros e mulatos, a classe operária com que ele topa por toda parte [...] fere a sensibilidade do europeu que acaba de deixar os costumes delicados e as fórmulas obsequiosas de sua pátria" (Martius apud Guimarães, M., 2000).

Em sociedades que não vivenciaram diretamente a presença da cultura clássica, suas academias e institutos históricos elegeram 
os tempos recuados como índice possível para a "antiguidade nacional".

Desta forma os valores da civilização não seriam apanágio exclusivo da tradição greco-romana, podendo inclusive ser encontrados num passado anterior a estes tempos e mesmo em sociedades que não teriam sido, a não ser muito tardiamente, marcadas pela presença dessa herança (Guimarães, M., 2001, p. 21).

No caso brasileiro, se as contradições do presente não forneciam os elementos necessários para a construção da consciência e identidade nacionais - a ponto de o próprio IHGB protelar ou mesmo impedir a divulgação de documentos relacionados ao passado imediato do Império $^{1}$-, nossos letrados recorreram aos registros exemplares dos homens e feitos dos tempos da colonização, bem como à natureza tropical para demarcar a singularidade de nossas origens.

Nesta política do "recordar para ser", a busca e a divulgação de um estoque memorial destacam-se nas publicações do principal veículo da agremiação, a Revista do IHGB. Em levantamento feito por Lucia Maria Paschoal Guimarães dos temas mais recorrentes na Revista entre 1839, ano da publicação de seu primeiro número, e o fim do Segundo Reinado, em 1889, evidencia-se a discrepância entre os 525 "documentos não contemporâneos" e as 153 "contribuições historiográficas". Somente nos anos de fundação

1 Segundo Lucia Maria Paschoal Guimarães, o arquivamento, o protelameno de publicações e até mesmo a censura de documentos a serem publicados na Revista do IHGB eram prática comum na associação beletrista, visando selecionar versões de episódios históricos mais compatíveis com o projeto político em curso e preservar a imagem de sócios envolvidos em momentos do processo de Independência e do Primeiro Reinado. Em 1847, o sócio Freire Alemão chega a propor a instituição de uma "arca do sigilo", destinada a guardar para a posteridade "[...] notícias históricas que alguém queira enviar, lacradas em cartas [...] que só serão abertas no tempo em que seu autor determinar" (Alemão apud Guimarães, 2011, p. 75). 
$|180|$

A Seiva e o Traço: História, Natureza e...

(1839-1849), foram transcritos uma média de 5,2 documentos não contemporâneos para cada contribuição historiográfica, demonstrando uma ênfase acentuada na formação de memória em detrimento da pesquisa historiográfica. A autora faz a ressalva de que tal descompasso pode ser em parte justificado pela carência inicial de fontes e a ausência de normas acadêmicas na seleção de sócios (Guimarães, L., 2011, p. 71-72). Mas em seguida destaca a orientação dada pelo primeiro-secretário do IHGB, Januário da Cunha Barbosa, no ensaio "Lembranças do que devem procurar os sócios [...] para remeteram à sociedade central", publicado no primeiro número da Revista, dando especial destaque à remessa de

biografias de brasileiros ilustres; cópias autênticas de documentos e extratos de notas pesquisadas em secretarias, arquivos, cartórios civis e eclesiásticos; notícias de costumes indígenas, lendas, sua catequese e civilização; descrições do comércio interno e externo das Províncias, seus principais produtos, rios, montanhas, portos, navegação e estradas; fundação, prosperidade e ou decadência de vilas, arraiais e suas populações (Ibidem, p. 75).

Para seguir tal orientação a contento, os sócios do IHGB deveriam não apenas reunir documentos relevantes de tempos recuados, como também redigir memórias e inventários sobre aspectos relevantes do passado nacional, principalmente de assuntos e realidades que careciam de registro escrito. Daí que a posterior organização de viagens exploratórias como a Comissão Científica, financiadas pelo Estado imperial, tenha se tornado uma das frentes para

salvar da indigna obscuridade [...] muitas memórias da pátria, e os nomes de seus melhores filhos; [...] o assento de suas cidades e vilas mais notáveis, a corrente de seus caudalosos rios, a área de seus campos, a direção de suas serras, e a capacidade de seus inumeráveis portos (Barbosa, 1839). 
Note-se que no texto do primeiro-secretário do IHGB colocam-se na mesma posição de importância os feitos dos homens e as peculiaridades da natureza, partes integrantes de um mesmo mundo que o viajante letrado deve interrogar e classificar, tornando-o assim tangível.

Em 1856, quando o zoólogo Manoel Ferreira Lagos lança a proposição de uma viagem exploratória às províncias mais longínquas do Império, fica igualmente patente que tal empreitada, a seu ver, serviria para atender diversos "níveis de conhecimento" do país e, por meio destas, alcançar-se-ia a completa integração deste império tropical.

O governo imperial ficaria melhor habilitado para conhecer as urgências do interior e decretar a abertura de novas vias de comunicação, que aumentariam as relações comerciais, e por conseqüência a renda nacional; muitas estradas já estão prontas pela natureza, só falta conhecê-las para por elas escorregarem as locomotivas. Alcançar-se-iam, igualmente, observações importantes sobre atmosferologia e climatografia, assim como a aquisição de preciosas coleções dos reinos orgânico e inorgânico para o nosso Museu; e quem sabe se talvez a descoberta de algum produto que em breve se tornasse rival dos mais lucrativos. Basta a descoberta de uma baga ou da folha de um arbusto para enriquecer qualquer Estado. O café, o chá, o mate, o cacau, o tabaco fazem girar cabedais quase incalculáveis (Lagos apud Braga, 1962, p. 16).

Relações de causa e consequência, avanços e conquistas ao alcance da mão, riquezas potenciais encobertas numa natureza luxuriosa, tudo isso apenas à espera de uma mão forte e uma razão firme a dirigir-lhe seus desígnios e bem servir o homem. E se a nação caminhava inexoravelmente rumo ao progresso civilizatório, também se fazia urgente dar conta de realidades que estavam prestes a desaparecer, como as últimas comunidades 
indígenas e os sertões incultos, a serem inventariados em laboratórios e museus. E como fazer isso se não pela experiência do deslocamento? Nesse sentido, o relato de viagem e a descrição de regiões desconhecidas ganham um papel fundamental na cultura ilustrada, estendendo-se às demandas da ciência moderna no intuito de preservar das brumas do esquecimento tanto os aspectos físicos quanto morais deste lado do Atlântico, organizando-os numa nova comunidade de sentido. "Esse olhar atento e rigoroso organiza o visível segundo um sistema de classificação e ordenamento, produzindo-o como nova visibilidade, agora submetida às regras da ciência moderna empenhada em percebê-los segundo sua utilidade" (Guimarães, M., 2007, p. 82-83).

Ao centrar foco no mundo natural, o IHGB seguia uma tradição de pesquisa e formação de inventários estabelecida desde o século XVIII, que também trazia em seu bojo objetivos políticos, econômicos e estratégicos. Ciosa em descobrir artefatos, técnicas, plantas ou minerais que reforçassem o erário real, a metrópole portuguesa, com o suporte intelectual da Universidade de Coimbra, tomou para si a incumbência de formar exploradores e naturalistas luso-brasileiros e enviá-los para devassar suas possessões coloniais. Segundo Raminelli, os vassalos ilustrados da Coroa, além de enviar produtos que pudessem dinamizar as trocas comerciais entre o império e o ultramar, deveriam remeter memórias, relatórios e desenhos de tudo o que vissem e ouvissem em suas viagens. "[...] A produção de inventários e a circulação de notícias permitiam tornar mais palpável a idéia de um império colonial, composto por possessões que aos poucos se integravam e tornavam-se interdependentes" (Raminelli, 2008, p. 214).

Em 1808, com a chegada da Família Real ao Rio de Janeiro e o fim do exclusivismo português, os portos do Brasil foram franqueados às "nações amigas", beneficiando não somente os interesses comerciais do Velho Mundo, mas também dando ensejo para que estes países enviassem representantes de suas respectivas academias e centros de saber para aqui empreender um "novo descobrimento". Karen Macknow Lisboa (1997) define a viagem 
científica empreendida no século XIX como uma etapa do processo do conhecimento norteado por um "projeto ilustrado", em que a atração pelo exótico, a pesquisa naturalista e o gosto pela errância se coadunam com interesses de esfera pública, como o desenvolvimento da ciência, a coleta de artefatos e formação de coleções para museus de história natural e a investigação de recursos potencialmente exploráveis.

No Brasil independente, as diversas formas de confronto dos doutos com os sertões (coleta de documentos, estudos históricos, viagens exploratórias etc.) concorreriam não apenas para a necessidade estratégica do governo imperial em conhecer as potencialidades geográficas e naturais de seu território, balizada tanto pela herança ilustrada quanto pelo historicismo de matriz romântica. Ao promover o escrutínio do país de si para si, buscava-se também "instituir um discurso de saber, de cariz nacional e devidamente autorizado (posto que assentado nos princípios de observação direta e rigor metódico) para inserir o país no prestigioso âmbito da comunidade científica internacional" (Silva Filho, 2006, p. 9).

Um nome importante para entender as preocupações sobre a formação da identidade nacional é Carl Friedrich von Martius, naturalista bávaro que dedicou a vida ao estudo da flora brasileira e sócio-correspondente do IHGB. Para o botânico, num tempo em que as fronteiras entre ciências naturais e humanas praticamente não existiam, a escrita da história de uma nação originada de sociedades iletradas passaria necessariamente pelo estudo das ciências naturais e da cultura material dos povos autóctones, na busca de um ordenamento inteligível da diversidade e exuberância do mundo tropical pela narrativa. Ressalta Manoel Luiz Salgado Guimarães, em artigo sobre o autor de Como se deve escrever a história do Brasil, que tal narrativa implicaria na experiência in loco dessas regiões e na construção de um saber capaz de organizar e hierarquizar os fenômenos observados, redefinindo as relações com o outro, o inculto, o não europeu.

Curiosamente, um dos componentes da comissão responsável por eleger a monografia vencedora do concurso 
proposto por Pedro II era justamente o botânico Francisco Freire Alemão, que viria a encabeçar o périplo pelos sertões cearenses. A comissão julgadora escolheu o trabalho de Martius em detrimento do texto de Henrique Julio Wallenstein, que propunha a narração e distribuição dos fatos dignos de se recordar pelo sistema de décadas. No parecer sobre o "Modo pelo qual se deve escrever a história do Brasil", a opção é justificada pelo alinhamento do texto de Martius às demandas da moderna historiografia e, por sua vez, às diretrizes que o próprio IHGB deseja imprimir à escrita da história pátria (Guimarães, M., 2007, p. 100).

Parece à comissão que o autor desta memória [Henrique Wallenstein] não compreendeu bem o pensamento do vosso programa, porquanto as vistas deste Instituto não se podiam contentar com a simples distribuição das matérias, e isto por um método puramente fictício, que poderá ser cômodo para o historiador, mas de modo algum apto a produzir uma história do gênero filosófico, como se deve exigir atualmente ${ }^{2}$ (grifo meu).

A defesa da propositura historiográfica de Martius, bem como a profícua troca de correspondência e colaborações científicas entre os dois botânicos, permite-nos inferir que as ideias do mestre bávaro eram, em grande parte, partilhadas por Freire Alemão. Talvez a trajetória do próprio Martius tenha pesado na decisão do sábio do Mendanha de se colocar, em plena maturidade, nesta empreitada, quem sabe igualando-se ou mesmo superando o mestre nas descobertas botânicas e na apreensão daquela realidade. Martius defende que o Brasil estaria caminhando rumo ao aperfeiçoamento, rompendo com o pensamento de nomes como Hegel e Buffon, que concebiam o continente americano como um mundo inacabado, imaturo. "O domínio sobre a natureza,

${ }^{2}$ Revista do IHGB (atas), Rio de Janeiro, n. 9, p. 279, 1847. 
a exclusão do 'selvagem', a miscigenação e a monarquia esboçam o alvorecer do jovem reino no horizonte das nações 'civilizadas', aproximando-o cada vez mais da história do Velho Mundo" (Lisboa, 1997, p. 26). Um cientista como Freire Alemão certamente ambicionava fazer parte de um projeto desse porte, compondo a escrita das memórias recolhidas diariamente na viagem pelo Ceará de acordo com os preceitos da historiografia legitimada por seus pares, a fim de que se tornasse, no futuro, fonte inquestionável para compor o passado da nação.

Viajar, ver e... relatar. Deslocar-se pelo sertão desconhecido e inóspito. Estar aberto e preparado para absorver todos os estímulos e vivências. Registrar de forma disciplinada, diária e detalhada tudo o que for experienciado. Os naturalistas-viajantes que percorreram o interior do país tiveram nessas três operações a base para a construção de uma memória que integrasse o conjunto dessas terras e gentes à história da humanidade, tornando o Brasil um país palpável aos olhos do mundo civilizado. Imbuídos desse espírito, os intelectuais do Instituto Histórico e Geográfico Brasileiro idealizaram a primeira expedição científica formada exclusivamente por doutos brasileiros, que percorreu o interior da província do Ceará e partes de Pernambuco e Piauí entre 1859 e 1861. Se os resultados não corresponderam às expectativas que os sábios e o monarca depositaram na viagem, o registro legado pelo botânico Freire Alemão oferece ao historiador um documento relevante para entender esse conjunto de tentativas e propostas de conhecimento da nação, buscando-se entrever na narrativa determinada prática de construção da memória e de certa configuração da temporalidade.

\section{Relatar é preciso}

No discurso proferido no Instituto Histórico e Geográfico Brasileiro (IHGB) em 30 de maio de 1856, Manoel Ferreira Lagos dirige-se ao imperador Pedro II, que presidia a sessão, e exorta-o sobre a necessidade de o governo "nomear uma comissão de 
engenheiros e naturalistas nacionais para explorar algumas das províncias menos conhecidas do Brasil". Lagos justifica tal necessidade ao questionar os resultados da viagem do conde de Castelnau às regiões centrais da América do Sul, e aproveita para dar conta de um sem número de imprecisões e equívocos que teriam sido cometidos por viajantes e naturalistas estrangeiros que aqui estiveram, censurando-os num tom "ora demasiado sarcástico, ora facêto" (Braga, 1962, p. 16-17). A proposta logo conquista a simpatia do monarca, que se dispõe a bancar a empreitada. Mas entre a espera pela liberação de verbas, a preparação das instruções de viagem e a compra de livros e instrumental científico na Europa - desde material de acampamento, medicamentos, equipamentos de precisão, microscópios e até câmeras fotográficas -, foram necessários três anos até que a expedição finalmente se pusesse em marcha.

A Científica foi dividida em cinco seções: Botânica, a cargo de Francisco Freire Alemão (que também era o presidente da Comissão); Geológica e Mineralógica, chefiada pelo engenheiro Guilherme Schüch de Capanema; Zoológica, destinada ao naturalista Manuel Ferreira Lagos (propositor da viagem exploratória); Astronômica e Geográfica, confiada ao matemático Giacomo Raja Gabaglia; e Etnográfica e Narrativa de Viagem, encarregada ao escritor e historiador Antonio Gonçalves Dias. Apesar de Gonçalves Dias ser o mais comumente lembrado pela posteridade por sua atividade literária, todos os membros da Comissão compunham a elite intelectual brasileira, ocupando à época cargos e funções importantes na estrutura do Império. Além dos adjuntos, mateiros e outros ajudantes, acompanhava a expedição o pintor José dos Reis Carvalho, ex-aluno de Debret e professor de desenho da Escola Imperial da Marinha.

A importância do registro escrito e imagético durante a viagem exploratória fica patente já nas "Instruções para a Comissão Científica encarregada de explorar o interior de algumas províncias do Brasil". Se o argumento era "corrigir" erros difundidos por viajantes estrangeiros, uma comissão formada exclusivamente por sábios brasileiros certamente deveria 
se esmerar na formação de memórias e coleções; uma preocupação presente, em maior ou menor grau, nos textos de todas as seções ${ }^{3}$. "É da maior vantagem que o naturalista viajante lance a cada noite em um livro as notas que houver tomado durante o dia, pois estas em papéis avulsos facilmente se podem extraviar". Entre outras vantagens, o caderno de anotações teria a função de aliviar o fardo da "memória de um viajante observador, que não deve contar sempre com ela, por mais feliz que a tenha" (Instruções... apud Braga, 1962, p. 194).

Nada deve escapar ao "perscrutador da natureza": descrições de rochas, animais e plantas, com seus nomes científicos, indígenas e vulgares. Lançar mão de todas as técnicas para melhor registro e conservação dos itens coletados, como descrições, desenhos e fotografias. "Rochas de aspecto característico serão fotografadas, e também se fará um nivelamento geológico, e um mapa [...]", prescreve o texto da Seção Geológica. Ao dissertar sobre as potencialidades das serpentes, Lagos ressalta a suma importância da coleta de lendas sobre estes animais entre os sertanejos. "Não se julgue futilidade o conhecimento dessas tradições teratológicas que a crença popular [...] vai transmitindo de boca em boca: arquivadas, quando mais não seja, servirão de tema para a poesia brasileira". Além disso, continua no texto da Seção Zoológica, a descoberta do mais frívolo inseto ou de uma propriedade encoberta em "poderes mágicos" pode ser o propulsor de indústrias que fazem girar imensos capitais, citando

\footnotetext{
${ }^{3}$ A elaboração de instruções para viagens científicas servia para orientar o naturalista sobre aspectos a serem explorados na região explorada, técnicas de conservação de espécimes, formas de registro das descobertas, entre outras orientações. No caso da Comissão Científica, ficou acertado que cada chefe de seção seria responsável pela elaboração de suas instruções. Porém, como Gonçalves Dias e Raja Gabaglia se encontravam na Europa para a compra de material para a expedição, o programa etnográfico e a parte de geografia e de astronomia foram escritos, respectivamente, por Manuel de Araújo Porto-Alegre e Cândido Batista de Oliveira (Braga, 1962, p. 20).
} 
como exemplo as tentativas efetuadas pela França de aclimatação de espécies exóticas do bicho-da-seda na Argélia (Ibidem, p. 189190).

Sob os auspícios de chuva e ventanias que descarregavam sua força sobre o vapor Tocantins, os membros da Comissão Científica de Exploração aportaram em Fortaleza em 4 de fevereiro de 1859. Após seis meses de preparativos e pesquisas nos arredores da capital cearense, Freire Alemão inicia seu percurso pelos rincões da província em 16 de agosto do mesmo ano, dedicando-se à coleta e estudo de plantas da região, bem como ao registro minucioso de aspectos da arquitetura, paisagens, costumes, linguagem e sociabilidade locais.

Um dos mais importantes cientistas de seu tempo, Freire Alemão tinha as credenciais necessárias para chefiar a expedição. Formou-se em medicina pela Academia Médico-Cirúrgica do Rio de Janeiro e em seguida doutorou-se pela Université de Paris, defendendo tese sobre o uso do iodo contra a "papeira". Voltando ao Brasil, foi lente de botânica e zoologia na agora Faculdade de Medicina do Rio de Janeiro e na Escola Central Militar. Nomeado médico da Imperial Câmara em 1840, mantinha boas relações com a família imperial, chegando a compor a comitiva encarregada de acompanhar a vinda da noiva de Pedro II, dona Teresa Cristina, e posteriormente a lecionar botânica para as princesas Isabel e Leopoldina. Fundou e participou ativamente de diversas associações científicas, entre elas a Sociedade Velosiana e o próprio IHGB (Damasceno; Cunha, 1964, p. 9-13).

Contava o botânico 62 anos de idade quando iniciou o périplo pela província cearense. Percorrendo a cavalo um território com poucos recursos, caminhos de difícil acesso e populações espargidas em fazendas e povoados miseráveis, percebe-se que a escrita se fazia a cada pouso, deitado na rede ou mesmo sobre as malas de viagem. Mais de uma vez registra em seu diário a terrível impressão que lhe causavam a água de beber, que classificava como "leitosa", "toldada", "suja". Também o desagradava a rusticidade das casas, agravada quando o abrigo era tão somente "debaixo duma árvore de pau branco desfolhada, 
exposta ao sol" (Alemão, 2011, p. 308). "Estamos escrevendo isto sentado na rede, com grande calor, e vento em postura (a casa está ainda aberta) e rodeados de galinhas, capotes, cabras e cachorros e também de meninos" (Ibidem, p. 319).

À falta de mobiliário, outros incômodos concorriam para dificultar uma escrita que exigia precisão, detalhismo e tempo. Nas vilas e cidades, havia grande concorrência de mendigos, cegos e aleijados a pedir esmolas nas casas em que se hospedavam, ou de velhos e senhoras para se "receitar" com o médico Freire Alemão. Já no campo, como parte da viagem foi empreendida em início de tempo invernoso, em várias passagens o botânico reclama da presença constante e incômoda de moscas e mosquitos, que ele atribui ao desasseio nas casas e nos currais das fazendas, onde observa os vaqueiros trabalharem metidos até as pernas num lamaçal "quase só de bosta" (Ibidem, p. 428).

\section{[...] quando todos se retiraram e que quis escrever [riscado "os nossos"] estes apontamentos, foi necessário, antes, formar fachos de papel e queimá- los pelas paredes; mas eram tantos, e vinha sempre reforço, que abandonei a empresa e pus-me a escrever atormentado por elas; além das moscas, de dia há mais uma espécie de mutuca, que se confunde com elas, que dão boas ferroadas (Ibidem, p. 434).}

Apesar de tantos problemas, a escrita era para o botânico um imperativo, como documento em que se pode divisar o fazer científico. Numa das passagens do diário, cuidando não perder nenhum detalhe em caminho, dizia diminuir a marcha do cavalo para fazer anotações enquanto colhia palmitos. Também descreve como uma conversa informal - que podia ocorrer nas rodas que se formavam à noite nas calçadas ou junto à família que dava pouso à expedição - dava-lhe ocasião para tomar notas. "Não fui à missa por ter que escrever", anota em 6 de novembro de 1859, um domingo. Mesmo doente, não deixa de participar a movimentação nas ruas em dia de festa, que aprecia da janela: 
"São sete horas da noite de Natal e escrevendo ouço grandes rumores nas ruas; é porque estão chegando para a missa da meianoite" (Ibidem, p. 168). Quando adoece, afirma que seu maior aborrecimento era quebrar a disciplina e não poder escrever em certos dias.

Naquelas páginas ele também encontrará espaço para explorar os sentimentos interiores. Num local em que a solidão e a sensação de estranhamento se faziam constantes, Freire Alemão registra detidamente a saudade da família, sentimentos melancólicos, problemas de saúde e mesmo os momentos de intriga e desacerto entre seus pares. Despeja no relato sentimentos que, no momento do ocorrido, precisou conter, mesmo diante das atitudes mais disparatadas e dos tratamentos menos amistosos, como quando acredita que Freirinho, seu sobrinho e assistente da Seção Botânica, faz-lhe uma crítica, como se aludisse que ele ficasse com o trabalho mais pesado, o de coleta, enquanto o tio se limitaria a fazer o estudo em casa. "Eu fiz reparo e disfarcei por estarem ali pessoas estranhas e não querer que eles notassem desgosto entre nós. Mas dói-me muito e tanto mais quanto era a sem-razão" (Ibidem, p. 146). Por vezes as situações mais amenas davam-lhe ensejo para arroubos melancólicos e românticos.

A despeito do aspecto desafiador de uma viagem exploratória para um homem no crepúsculo da vida, acostumado a todos os confortos da Corte, não é difícil imaginar que a Comissão representaria, para ele como para qualquer outro naturalista de seu tempo, o coroamento de sua trajetória profissional. Só da Seção Botânica, o botânico pretendia compor o Catálogo Sistemático das Plantas Colhidas no Ceará, a Flora Cearense, o Estudo da Geografia Botânica do Ceará e a Narração da Viagem pelo Interior da Província do Ceará (Braga, 1962, p. 95).

Assim, a disciplina do registro, a apreensão do espaço pelo controle do tempo, o estabelecimento de rotinas e ritmos na e pela escrita indicam que o trabalho de Freire Alemão era regido pela ideia de que "o mundo natural escondia, por trás de uma aparente desordem, uma ordem, a qual obedeceria a princípios claros, racionais, lógicos". Tais princípios tornar-se-iam grandes 
aliados no estabelecimento de um saber ilustrado, que buscava se diferenciar do conhecimento mediado pelo divino, em que a natureza era "o espaço ideal de construção do saber, posto que permitia o contato direto entre o objeto do conhecimento e o sujeito que o construía" (Coelho, 2010, p. 33).

Mas os contratempos e dificuldades logo se fizeram conhecidos nas páginas dos jornais, ensejando na opinião pública uma visão crítica do empreendimento. Incidentes envolvendo ajudantes da Comissão, desacertos entre os chefes de seções, problemas ligados às especificidades da região e até a tentativa frustrada de aclimatação de 14 camelos para realizar a travessia foram amplamente noticiados pela imprensa local e da Corte. Criticava-se também a aparente irrelevância dos estudos realizados e a falta de descobertas que correspondessem às despesas empregadas. Todos esses problemas legaram à Comissão Científica epítetos nada lisonjeiros, como "Comissão Defloradora" remetendo a supostas incursões sexuais dos científicos com a "gente do belo sexo" cearense - e "Comissão das Borboletas" aludindo à inutilidade do projeto (Kury, 2001, p. 29).

Um ano antes de iniciar a viagem, Capanema já previa a incompreensão do trabalho que seria realizado, em cartas ao amigo Gonçalves Dias. Ainda que fossem chefes de seção da empreitada, no campo pessoal ambos tinham uma posição crítica em relação à Científica, chamada entre os dois compadres de "excursão tupi". Capanema chega a comparar os dividendos que um engenheiro responsável por construir estrada de ferro teria, em relação ao trabalho na Comissão do Ceará. "Quanto à glória, nosso papalvo me chamará de homem imenso por ter feito um caminho de ferro, enquanto se eu descobrir no Ceará que a formação cretácea é mais antiga que a carbonífera, o que poria o Instituto de França de pernas para o ar, aqui me chamariam de toleirão" (Capanema apud Kury, 2001, p. 37).

Esta citação é importante para dimensionar a distância entre as altas pretensões da elite intelectual, em seu projeto de formação da consciência e identidade nacionais, e as demandas de quem vivia fora da "ilha de letrados", voltadas para questões da vida 
prática. No diário de Freire Alemão há várias alusões a estes momentos de alteridade e incompreensão entre os "científicos" e a "gente do país":

Depois disso nos fomos deitar nas redes, e ele sentado num banquinho não cessou de falar, fazendo-nos questões às vezes impertinentes. Contava ele que nós (digo, a comissão) vínhamos ao Ceará descobrir minas de metais preciosos, fartar a província de águas e ensinar a trabalhar: "Porque, dizia ele, nós estamos ainda muito brutos; na sua terra (parecia que se referia à Europa) há tantos meios de abreviar o trabalho que nós desconhecemos, vejo coisas vendidas por preço tal que seria impossível fazê-los entre nós" (isto é, o Ceará); referia-se sem dúvida aos artefatos europeus. "Eu aqui tenho tanto trabalho para plantar, limpar e de fazer a mandioca em farinha, desejava ver algum meio de fazer esse serviço mais depressa"; e era nisto, como em outras coisas, que ele esperava que a comissão desse ou ensinasse modos de facilitar os trabalhos, e quando eu the expliquei qual era o objeto da minha seção e da do Lagos, o homem caiu das nuvens e não podia compreender-me; e enfim disse: "Já vejo que com os senhores não ganho nada" (Alemão, 2011, p. 46-47).

De volta ao Rio de Janeiro, os produtos trazidos do Ceará foram objeto de várias exposições públicas, tendo sido incluídos na mostra de produtos nacionais levada para a Exposição Universal de 1862, em Londres. Mas não houve nenhuma grande publicação dos resultados da expedição, como inicialmente se ambicionava. A exemplo de outros acervos de naturalistas brasileiros, ${ }^{4}$ o material

\footnotetext{
${ }^{4}$ Flora Süssekind lista o extravio ou a perda dos acervos do baiano Joaquim de Amorim Castro e do mineiro Conceição Veloso. Os escritos e coleções de outro naturalista baiano, Alexandre Rodrigues Ferreira, resultado de dez anos de pesquisa do Pará ao Mato Grosso, também tiveram fim semelhante, a ponto de não se conseguir identificar o que fazia parte de seu acervo (Süssekind, 2008, p. 72-73).
} 
recolhido durante a viagem exploratória ficou intocado ou se extraviou em arquivos e depósitos por décadas. A morte prematura de alguns dos membros da Comissão ${ }^{5}$, os problemas de saúde que limitaram o trabalho de Freire Alemão, a transferência de recursos para a guerra contra o Paraguai e o fato de Capanema e Lagos terem assumido cargos na estrutura do Império também contribuíram para o esparsamento de publicações em relação ao vasto acervo trazido da província cearense. Foram necessários 145 anos para que o diário de viagem redigido pelo botânico ganhasse sua primeira publicação.

Se, por um lado, lamenta-se que um documento de tal envergadura não tenha ganhado a divulgação que mereceria em seu tempo, por outro a manutenção do texto de Freire Alemão em seu estado bruto enseja uma oportunidade peculiar de investigação histórica. Como texto gerado a partir de uma demanda do Estado imperial, fatalmente sofreria supressões de diversas ordens, caso tivesse sido publicado. Tais supressões poderiam incluir desde questões de foro privado, informações confidenciais e de interesse estatal até opiniões que pudessem ofender susceptibilidades, caso fossem divulgadas ainda em vida do autor e das pessoas ali tratadas. Por conta disso, o relato de Freire Alemão, quando confrontado com outras memórias de viagem, apresenta componentes peculiares ao pesquisador. Não apenas pela descrição pormenorizada das impressões sobre a terra e forma de viver de seu povo, da relação, nem sempre cordial, do botânico com os demais membros da Comissão Científica e mesmo a exposição detalhada de defluxos, febres, disenterias e outros problemas de saúde que o acometeram ao longo do caminho.

\footnotetext{
${ }^{5}$ Manuel Freire Alemão, o Freirinho, sofreu uma ruptura de aneurisma em 14 de maio de 1863. Botânico assistente de Freire Alemão durante a viagem ao Ceará, esperava-se que ele desse continuidade ao legado do tio, já em idade avançada. Um ano depois, após tratamentos de saúde malfadados na Europa, Gonçalves Dias morreria no naufrágio do navio que o trazia de volta ao Brasil, sem escrever o relatório da Seção Etnográfica (Braga, 1962, p. 90-99).
} 
Para dimensionar a necessidade de levar em conta as marcas de enunciação no relato de Freire Alemão dentro do projeto de formação da identidade nacional, é preciso levar em conta duas questões, aparentemente contraditórias, que, no entanto, revelam a complexidade da experiência legada por descrições, correspondências e diários de viagem. Diferentes de outros relatos descompromissados ou de cunho eminentemente intimista, compor memórias escritas no decorrer de um percurso era fundamental para o trabalho de viajantes em expedições científicas. Tais escritos poderiam servir como suporte para pesquisas ulteriores, socorrendo "falhas da memória" ou permitindo um confronto descritivo para os espécimes que, para serem conservados, acabavam por sofrer alterações físico-químicas, para citar apenas dois exemplos.

Nesse sentido, o dever de profissão e a formação desses naturalistas faziam com que tivessem uma percepção aguçada para tudo o que vissem, ouvissem ou experimentassem na vida cotidiana das populações visitadas, configurando-se assim numa fonte importante para depreender os costumes, as tensões e as vivências sociais na esfera pública e no domínio privado nos territórios do chamado Novo Mundo. "Como estranho ao grupo, [o naturalista] observa padrões de comportamento e idéias que passam despercebidas ao habitante do país. [...] O óbvio, para o habitante, pressupõe no viajante um ato de espanto e interrogação" (Leite, 1997, p. 18).

Por outro lado, não se pode concluir que essas observações fossem neutras, como se quer fazer crer o discurso científico de então. Tais sociabilidades eram "percebidas e descritas mediante olhares comprometidos com a gramática comportamental burguesa que se constituiria ao longo do século XIX" (Marins, 2001, p. 29). Assim, a percepção alargada pelas demandas da exploração de ambientes, costumes e gentes tão díspares do que esses naturalistas vivenciaram em seus países de origem não deixou de ser filtrada por pressupostos que, não raro, balizavam o contato com o outro pelo viés da superioridade do observador. 
De fato, como observa Karen Lisboa, relatar era preciso, na dupla acepção da palavra: necessidade e precisão. A narrativa composta para dar conta de uma empresa que poderia gerar resultados significativos, como no caso dos autores de Viagem pelo Brasil. Uma narrativa também comprometida em contar a "verdade", valendo-se do olhar armado pelo conhecimento das ciências naturais (Lisboa, 1997, p. 45-46). Porém, o resultado dessa dupla percepção são relatos que, como alertou Lagos, trazem muitas vezes avaliações equivocadas e/ou que não levam em conta as particularidades da vivência social de uma ex-colônia tornada império nos trópicos, com todas as contradições e embates dessa experiência única na História. $\mathrm{O}$ exíguo tempo de permanência numa vila ou cidade, além do desconhecimento dos códigos que regiam as sociabilidades locais, poderia levar a uma descrição e análise dos costumes da gente do país embasados pelo prisma do exótico e, muitas vezes, do atraso em comparação com o Velho Mundo. Se não é possível analisar a Comissão Científica em termos de "sucesso" ou "fracasso", não se pode negar que o legado dessa expedição, deixado nas principais instituições científicas e históricas do país, é de grande relevância para entender as complexas operações envolvidas na construção do "ser brasileiro".

\section{Bibliografia}

ALEMÃO, F. F. Diário de viagem de Francisco Freire Alemão (18591861). Fortaleza: Fundação Waldemar Alcântara, 2011.

BARBOSA, J. C. "Discurso no ato de estatuir-se o IHGB". Revista do Instituto Histórico e Geográfico Brasileiro, Rio de janeiro, v. 1, n. 1, p. 9-17, 1839.

BRAGA, R. História da Comissão Científica de Exploração. Fortaleza: Imprensa Universitária do Ceará, 1962.

CARVALHO, J. M. A construção da ordem: a elite política imperial. Teatro de sombras: a política imperial. $6^{\mathbf{a}}$ ed. Rio de Janeiro: Civilização Brasileira, 2011. 
COELHO, M. C. A epistemologia de uma viagem. São Paulo: Livraria da Física, 2010.

DAMASCENO, D.; CUNHA, W. Os manuscritos do botânico Freire Alemão, catálogo e transcrição. Rio de Janeiro: Divisão de Publicações e Divulgação da Biblioteca Nacional, 1964.

GUIMARÃES, L. M. P. Debaixo da imediata proteção imperial: Instituto Histórico e Geográfico Brasileiro (1838-1889). $2^{\underline{a}}$ ed. São Paulo: Annablume, 2011.

GUIMARÃES, M. L. S. "História e natureza em von Martius: esquadrinhando o Brasil para construir a nação". História, Ciência, Saúde - Manguinhos [online], Rio de Janeiro, v. 7, n. 2, p. 391-413, 2000. Disponível em: <http://www.scielo.br/ scielo.ph p ? script=sci_arttext\&pid=S 0104 59702000000300008\&lng=en\&nrm=iso>. Acesso em: 27 ago. 2012.

. "Para reescrever o passado como história: o IHGB e a Sociedade dos Antiquários do Norte". In: HEIZER, A.; VIEIRA, A. A. P. (org.). Ciência, civilização e império nos trópicos. Rio de Janeiro: Access, 2001.

. "Entre as Luzes e o Romantismo: as tensões da escrita da História no Brasil oitocentista". In: GUIMARÃES, M. L. S. (org.). Estudos sobre a escrita da história. Rio de Janeiro: 7 Letras, 2007.

KOSELLECK, R. Futuro passado: contribuição à semântica dos tempos históricos. Rio de Janeiro: Contraponto/Editora PUCRio, 2006.

KURY, L. "A Comissão Científica de Exploração (1859-1861): a ciência imperial e a musa cabocla". In: HEIZER, A.; VIDEIRA, A. A. P. (orgs.). Ciência, Civilização e Império nos Trópicos. Rio de Janeiro: Access, 2001. 
LEITE, M. L. M. Livros de viagem (1803-1900). Rio de Janeiro: UFRJ, 1997.

LISBOA, K. M. A Nova Atlântida de Spix e Martius: natureza e civilização na Viagem pelo Brasil (1817-1820). São Paulo: Editora Hucitec, 1997.

MARINS, Paulo César Garcez. Através da rótula: sociedade e arquitetura urbana no Brasil, séculos XVII a XX. São Paulo: Humanitas/FFLCH/USP, 2001.

MENEZES, U. B. "A História, cativa da memória? Para um mapeamento da memória no campo das Ciências Sociais". Revista do Instituto de Estudos Brasileiros, São Paulo, n. 34, 1992.

RAMINELLI, R. Viagens Ultramarinas: monarcas, vassalos e governo a distância. São Paulo: Alameda, 2008.

SCHWARCZ, L. M. O espetáculo das raças: cientistas, instituições e questão racial no Brasil (1870-1930). São Paulo: Companhia das Letras, 1993.

SILVA FILHO, A. L. M. "Nota Explicativa”. In: ALEMÃO, F. F. Diário de Viagem de Francisco Freire Alemão. Fortaleza-Crato, 1859. Fortaleza: Museu do Ceará, 2006.

SÜSSEKIND, Flora. O Brasil não é longe daqui: o narrador; a viagem. $3^{\underline{a}}$ reimpressão, São Paulo, Companhia das Letras, 2008. 